\title{
CLASSIFICAÇÃO GEOMORFOLÓGICA E O CÓDIGO FLORESTAL BRASILEIRO: CONSIDERAÇÕES SOBRE AS RELAÇÕES DE USO DO SOLO NA SUB-BACIA HIDROGRÁFICA DO RIO MANDU
}

\author{
Gustavo Costa Teixeira ${ }^{\text {(a) }}$, André dos Santos Ribeiro ${ }^{(b)}$, André Silva Tavares ${ }^{(c)}$, Ronaldo Luiz \\ Mincato $^{(d)}$
}

(a) Departamento de Engenharia/Universidade Federal de Lavras - UFLA, gustavo.costa.t@ hotmail.com

(b) Centro de Ensino Superior em Gestão, Tecnologia e Educação - FAI, andreribeiro@ fai-mg.br

(c) Insituto de Ciências da Natureza/Universidade Federal de Alfenas - UNIFAL-MG, andresttavares@gmail.com

(d) Insituto de Ciências da Natureza/Universidade Federal de Alfenas - UNIFAL-MG, ronaldo.mincato@ unifalmg.edu.br

\section{EIXO: BACIAS HIDROGRÁFICAS E RECURSOS HÍDRICOS: ANÁLISE, PLANEJAMANETO E GESTÃO}

\begin{abstract}
Resumo
Para avaliar o ambiente e suas alterações é preciso avaliar os atributos do meio físico que permitam identificar áreas críticas ou frágeis, em relação ao uso e ocupação, que devem ser protegidas por políticas públicas. No caso do Brasil, o Código Florestal normatiza as regras de uso do solo para todo o país. Neste contexto, a aplicação de algumas normas do código foi avaliada para o caso da Subbacia Hidrográfica do Rio Mandu, permitindo algumas considerações sobre as relações de uso. Isto resultou em um cenário com predomínio de práticas deletérias ao ambiente, com o não cumprimento das regras para Áreas de Preservação Permanete e Reserva Legal.
\end{abstract}

Palavras chave: Bacia Hidrográfica; Sul de minas; APP; Reserva Legal; Uso do Solo.

\section{Introdução}

As ações humanas que causam danos à biodiversidade, ao clima, à qualidade das águas ou à saúde de florestas e solos precisam ser diminuídas. A procura por melhores políticas ambientais, contudo, requer que consideremos não só o "homem" contra a natureza, mas também o inverso e que seja assumido o que a ciência mostra sobre o comportamento da natureza. Ignorar o que as Ciências da Terra têm revelado, nas últimas décadas, sobre as mudanças naturais e seus efeitos nas pessoas e sociedades continuará a produzir políticas, atitudes e crenças ambientais equivocadas sobre como o mundo natural funciona (BERGER, 2007).

A alteração da estrutura e das condições de funcionamento e de autorregularão dos sistemas ambientais naturais pode vir de diferentes impactos humanos, como desmatamento, construção de obras hidrotécnicas, impermeabilização da superfície do solo e irrigação descontrolada (RODRIGUEZ et al., 2002). 
Para avaliar o ambiente e suas alterações, Pereira (2012) destaca que a avaliação dos atributos do meio

físico permite identificar áreas críticas ou frágeis, em relação ao uso e ocupação, que devem ser protegidas por políticas públicas. Rufino (2002) complementa que a ausência, carência ou a má aplicação de políticas públicas de planejamento provocam sérios problemas ambientais, tais como, a poluição do ar, das águas, dos solos, enchentes, erosões, assoreamentos, deslizamentos e supressão da vegetação nativa, que trazem consequências negativas aos ecossistemas e a população.

Diante destas questões, este trabalho objetivou relacionar a geomorfologia da Sub-bacia Hidrográfica do Rio Mandu com o novo Código Florestal, explicitando as relações de uso do espaço e as vulnerabilidades.

\section{Referencial Teórico}

A vulnerabilidade é a susceptibilidade dos ambientes de sofrerem danos decorrentes dos processos erosivos e está relacionada com fatores de desequilíbrio de ordem tanto natural, oriundos da própria dinâmica do ambiente, como em situações de elevadas declividades e alta erodibilidade dos solos, quanto antropogênica, com o mau uso do solo (CABRAL et al., 2011).

Para Ross (2012), os indicadores da vulnerabilidade ambiental são o uso do solo, a geologia, o relevo, o clima e os solos. De acordo com Ribeiro et al. (2016), para a sub-bacia em questão, essas relações se modificam, restando usos do solo e relevo como principais fatores envolvidos com a dinâmica da paisagem atual.

Neste contexto, as normas explicitadas pelo Código Florestal Brasileiro (BRASIL, 2012), tornam-se ainda mais relevantes. O Código Florestal é um mecanismo legal que regulamenta a distribuição territorial dos usos do solo considerando as fragilidades ambientais, portanto, auxilia na manutenção da estabilidade dos fluxos de materiais e energia no ambiente. Ele estabelece as normas para a proteção da vegetação nativa no Brasil, estabelecendo, dentre outros tipos de unidades de preservação e conservação, as Áreas de Preservação Permanente (APP), as de Preservação Ambiental (APA) e as de Reserva Legal.

Neste contexto, são delimitadas como Áreas de Preservação Permanente (APP) as de elevada fragilidade ou de elevada importância em termos de preservação, para as quais não são permitidos usos alternativos que não sejam pela vegetação nativa. Tais áreas correspondem as faixas marginais de qualquer curso d'água natural, o entorno de nascentes, olhos d'água perenes, lagos e lagoas naturais e reservatórios artificiais, encostas com elevada declividade $\left(45^{\circ}\right)$ e topo de morros, montes, montanhas e serras (BRASIL, 2012). 
Por sua vez, as Área de Proteção Ambiental (APA) são geralmente áreas extensas que permitem usos alternativos, mas sem causar danos severos aos atributos abióticos, bióticos, estéticos e culturais, importantes para a qualidade de vida e o bem-estar das populações humanas. Assim, um dos principais objetivos é a proteção da diversidade biológica, orientação do processo de ocupação e garantia de uso sustentável dos recursos naturais (BRASIL, 2012).

Já a Reserva Legal, corresponde à área localizada no interior de uma propriedade ou posse rural, com a função de assegurar o uso econômico de modo sustentável dos recursos naturais, auxiliar quanto à conservação e a reabilitação dos processos ecológicos e promover a conservação da biodiversidade, bem como o abrigo e a proteção de fauna silvestre e da flora nativa (BRASIL, 2012). O novo Código Florestal aponta o acréscimo das APP como parte da Reserva Legal, segundo Zanatta, Lupinacci e Boin (2016) a diferença conceitual de proteção e preservação tornou-se insignificante com essa medida.

\section{Materiais e Métodos}

\section{Área de Estudo}

A Sub-bacia Hidrográfica do Rio Mandu possui cerca de $500 \mathrm{~km}^{2}$, com altitudes entre 820 e $1.494 \mathrm{~m}$. Está localizada na região Sul de Minas Gerais e pertence a Sub-bacia Hidrográfica do Rio Sapucaí, afluente do Rio Grande. Abrange parte dos municípios de Borda da Mata, Estiva, Ouro Fino e Pouso Alegre (Figura 1). O Rio Mandu possui grande importância histórica e cultural, ressaltada por Gouvêa (2004) e econômica, uma vez que contribui com 100\% do abastecimento da área urbana de Borda da Mata e $71 \%$ do abastecimento da de Pouso Alegre (ANA, 2015), município com a $2^{\mathrm{a}}$ maior população do sul de minas, estimada em 142,072 habitantes (IBGE, 2014). 


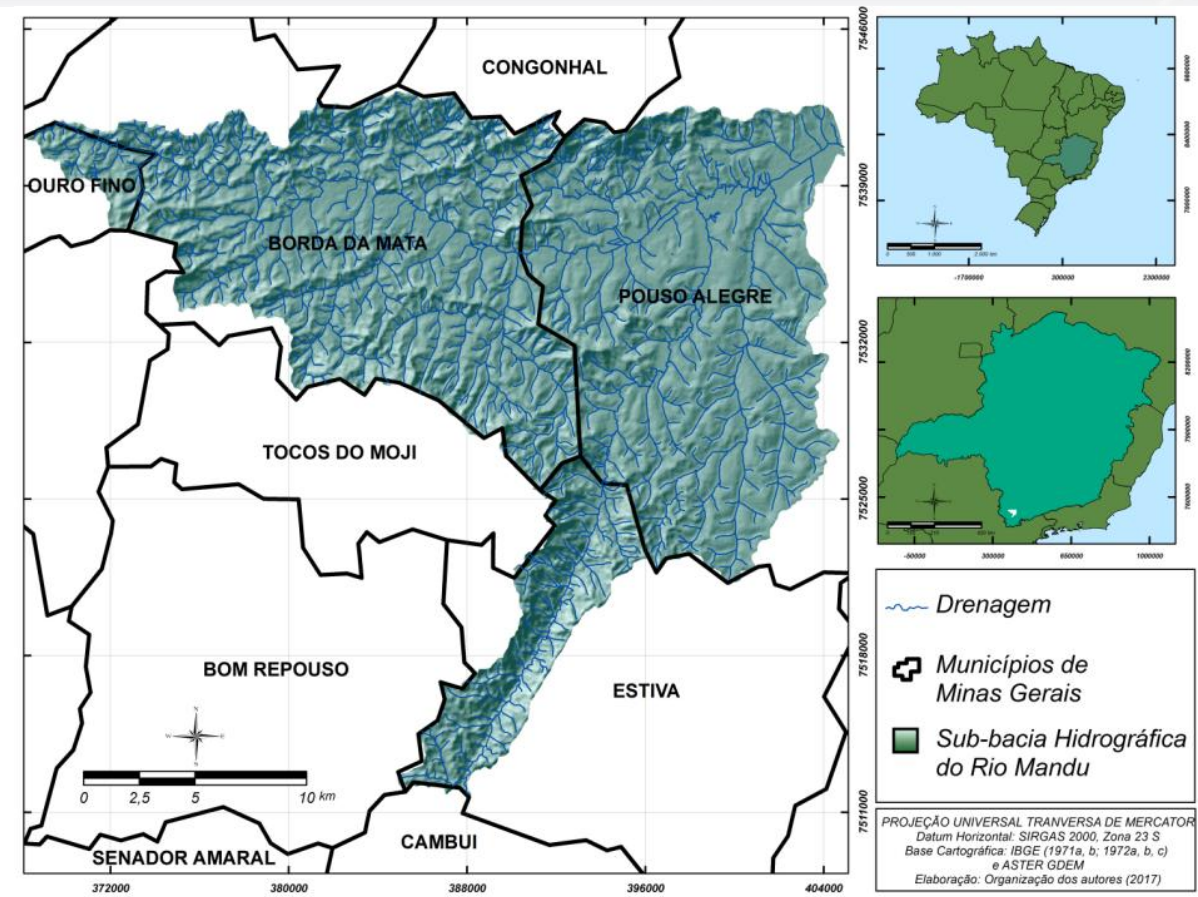

Figura 1- Mapa localização da Sub-bacia Hidrográfica do Rio Mandu.

Em termos de geologia, CPRM (1998) caracterizou unidades graníticas, gnáissicas e migmatíticas para os relevos mais elevados e sedimentares para as formas rebaixadas. De maneira mais específica, ocorrem granitos, ortognaisses, e gnaisses migmatizados nas maiores altitudes da borda norte. Nos relevos similares da borda sul e sudoeste, há granitos, granito-gnaisse, gnaisses migmatizados, gnaisses charnoquíticos e migmatitos. Os relevos mais dissecados da área central da sub-bacia também são sustentados por gnaisses charnoquíticos. Já na porção leste, a jusante, ocorrem coberturas cenozoicas indiferenciadas, que configuram morfologias de colinas amplas e pequenos morros que se estendem até as áreas de deposição do rio.

Em relação aos solos, as unidades da sub-bacia foram classificadas por Ribeiro et al. (2016) baseados no mapa de solos de Minas Gerais (FEAM, 2010). De acordo com Ribeiro et al. (2016), a formação das unidades de solo da sub-bacia remete a um intenso intemperismo do material rochoso pela ação da água e, disto, resultaram solos com horizonte superficial argiloso, distróficos e predominantemente profundos. Cabe destacar os Cambissolos Háplicos e Argissolos Vermelho-amarelo associados aos relevos mais íngremes, os Latossolos Vermelho-Amarelo e Vermelho aos relevos intermediários e os Neossolos Flúvicos e Gleissolos Háplicos aos relevos deposicionais.

Neste contexto, foi feito o mapeamento da hidrografia por meio da digitalização no aplicativo ArcGIS 10.1 da drenagem perene das cartas topográficas do Instituto Brasileiro de Geografia e Estatística - IBGE 
(1:50.000) folhas Santa Rita de Caldas (SF-23-Y-B-I-1), Ipuiúna (SF-23-Y-B-I-2), Borda da Mata (SF-23Y-B-I-4), Pouso Alegre (SF-23-Y-B-II-1) e Conceição dos Ouros (SF-23-Y-B-II-3).

Utilizando o mesmo aplicativo, foi feito o mapeamento geomorfológico a partir da vetorização da morfologia do relevo. A metodologia adotada foi a da taxonomia de classificação do relevo de Ross (1992), feita do nível macro para o micro, das grandes estruturas ( $1^{\circ}$ Táxon) até as formas de processos atuais em vertentes (6 $6^{\circ}$ Táxon). Assim, a classificação seguiu até o $3^{\circ}$ Táxon, a partir das Unidades Morfoestruturais (1º́xon), Maciços do Alto Rio Grande e Depressão do Sapucaí. Estas duas unidades foram separadas em quatro Unidades Morfoesculturais ( $2^{\circ}$ Táxon): Domínio dos Sedimentos Indiferenciados da Depressão do Sapucaí, Domínio dos Complexos Granitoides dos Planaltos do Alto Rio Grande, Domínio dos Complexos Metamórficos do Planalto da Mantiqueira e Domínio dos Complexos Metamórficos dos Planaltos do Alto Rio Grande. Então, foi elaborada a cartografia síntese de Unidades Morfológicas ou de padrões de formas semelhantes ( $3^{\circ}$ Táxon) e foram definidas as 8 subunidades seguintes: Planalto da Mantiqueira, Escarpas do Planalto da Mantiqueira, Cristas e Escarpas Setentrionais, Blocos Serranos Intermediários, Serras Baixas, Morros, Colinas e Planície Fluvial.

Em termos de materiais, a classificação foi feita a partir de produtos intermediários oriundos das cartas topográficas (ibid), de sensoriamento remoto e checagens em campo. Os produtos intermediários utilizados para classificação das unidades de relevo foram os mapas de Índice de Dissecação do Relevo, elaborado de acordo com Ross (1994), Hipsométrico, Clinográfico e as imagens de relevo sombreado e uma composição colorida com infravermelho, para ressaltar as formas. Além destes produtos, a classificação também considerou os aspectos morfotectônicos e morfoestruturais e de padrãos de forma apontados por Magalhães Jr. e Trindade (2005) e Machado e Silva (2010) e de padrões de drenagem por Magalhães Jr. e Diniz (1997).

Detalhadamente, foi usada uma composição colorida feita com imagens do sensor Operational Land Imager (OLI) do satélite Landsat 8, nos canais espectrais 5R $(0,85-0,88 \mu \mathrm{m}), 4 \mathrm{G}(0,630-0,680 \mu \mathrm{m}), 3 \mathrm{~B}$ $(0,525-0,600 \mu \mathrm{m})$, fundidas com o canal 8 pancromático $(0,500-0,680 \mu \mathrm{m})$, para aumentar a resolução espacial de 30 para $15 \mathrm{~m}$. Adiante, foi empregada a imagem do relevo sombreado, pelo Modelo Digital de Elevação (MDE) Advanced Spaceborne Thermal and Reflection Radiometer Global Digital Elevation Map (ASTER GDEM) da NASA (2015).

Por sua vez, os usos do solo foram classificados em mata nativa, área urbana, culturas temporárias, café, eucalipto, pastagens e solo exposto. Para tanto foi usado o método de segmentação da imagem, com dados da composição colorida (4R, 3G e 2B) do sensor OLI Landsat-8, com fusão da composição colorida com a banda 8 pancromática. Em seguida, foi feita classificação por segmentos no aplicativo ENVI 5.0, 
com os limiares de nível de escala e nível de dissolução, respectivamente com os valores, 60 e 65 . O desempenho foi julgado visualmente. Após, foram extraídos os atributos espaciais, espectrais, texturais, de cor e razão de bandas, que serviram de base para classificação dos usos do solo.

\section{Resultados e Discussão}

As formas de relevo encontradas na sub-bacia hidrográfica do Rio Mandu foram: o Planalto da Mantiqueira, as Escarpas do Planalto da Mantiqueira e as Cristas e Escarpas Setentrionais, com as maiores altitudes e declividades. Os Blocos Serranos Intermediários, as Serras Baixas, os Morros e as Colinas, como áreas de transição entre as áreas mais altas e a Planície Fluvial, com as menores declividades e altitudes.

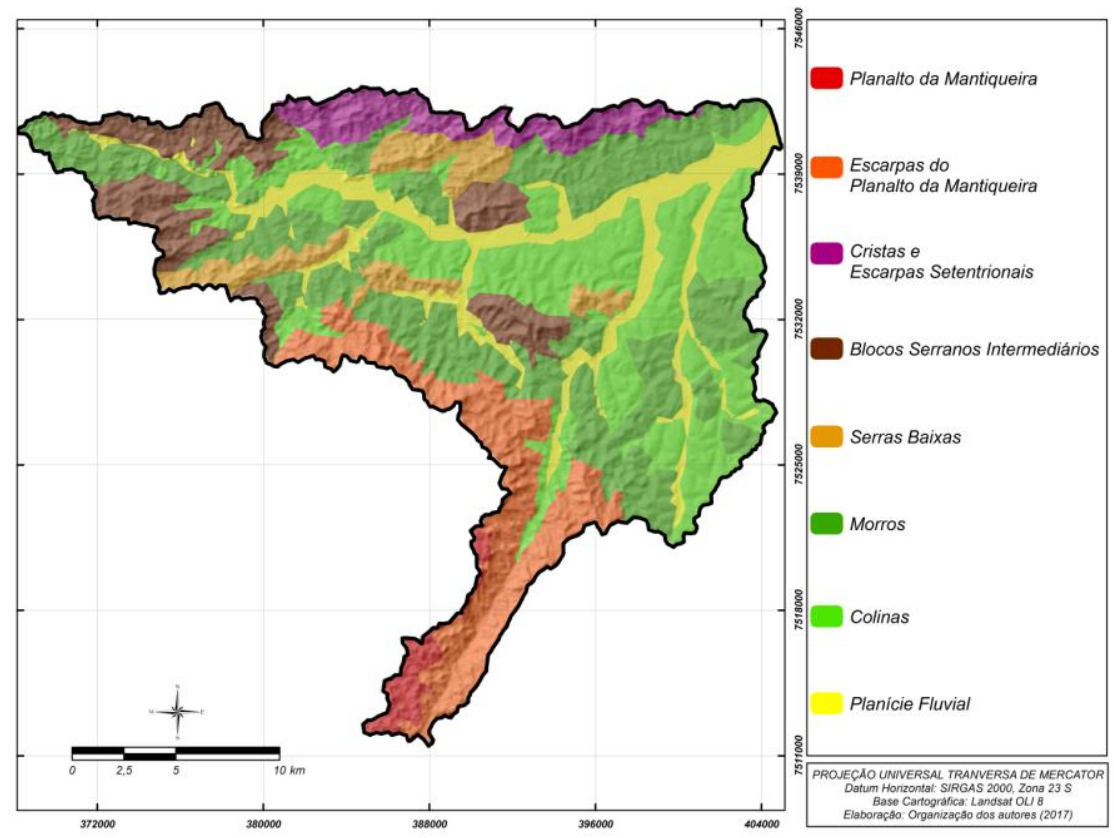

Figura 2 - Mapa Geomorfológico da Sub-bacia Hidrográfica do Rio Mandu.

Em relação aos usos do solo (Figura 3), foram identificados os seguintes tipos de uso do solo: pastagem representando $58,9 \%$ da área, seguido por culturas temporárias com 19,8\%, mata nativa $13 \%$, solo exposto 5\%, área urbana 2,3\% (representam as áreas urbanas de Borda da Mata e parte da área urbana de Pouso Alegre), café $0,7 \%$ e eucalipto $0,3 \%$. 

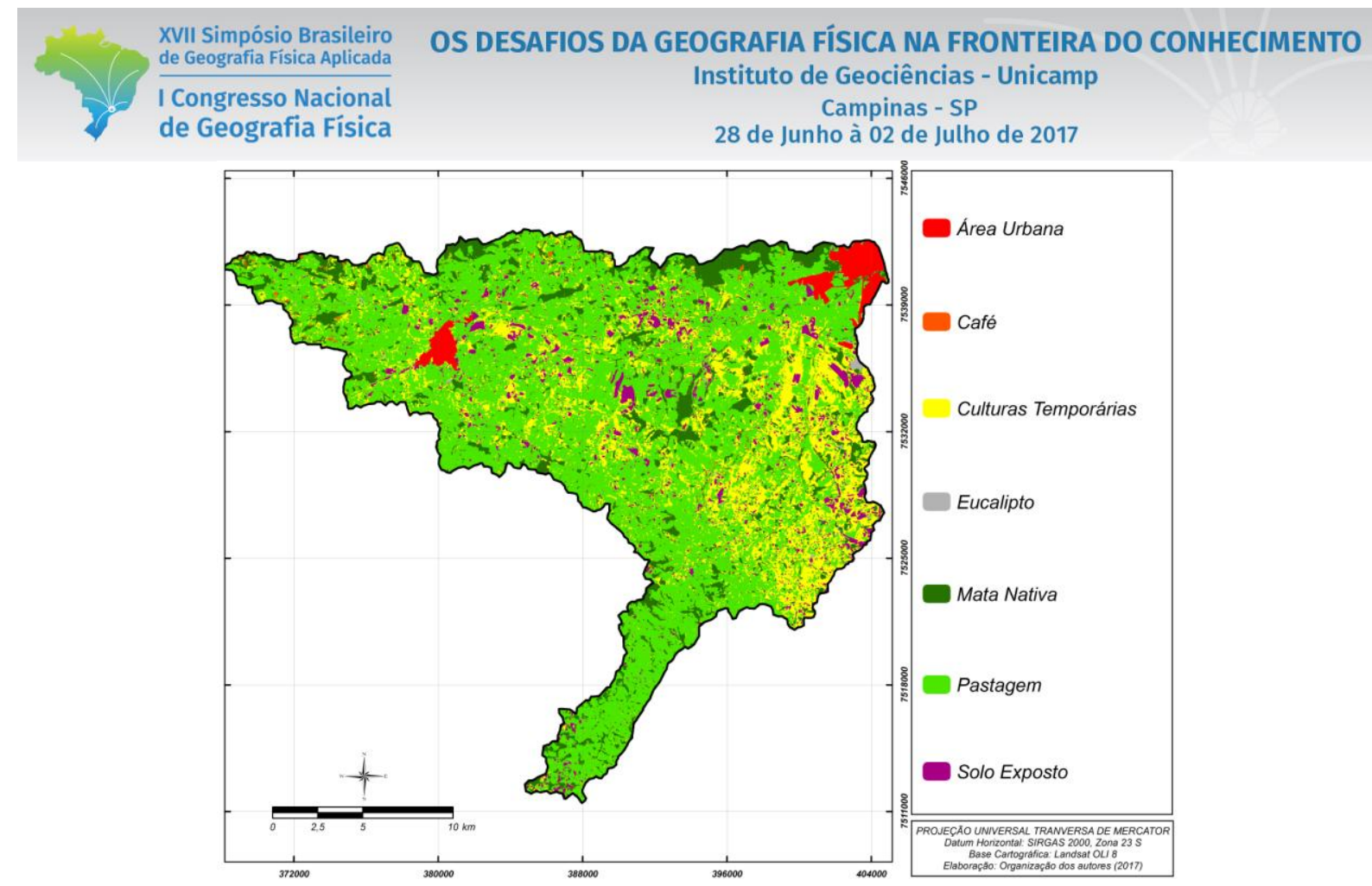

Figura 3 - Mapa de Uso e do Solo da Sub-bacia Hidrográfica do Rio Mandu.

Dentre as unidades geomorfológicas as que apresentam maior declividade média percentualmente são: Escarpas do Planalto da Mantiqueira com 49,1 \%, Cristas e Escarpas Setentrionais com 44,8\%, Blocos Serranos Intermediários com 32,8\% e Serras Baixas com 21,7\%. Nestas unidades, com destacada vulnerabilidade à processos erosivos, a mata nativa e fragmentos de mata aparecem como segundo tipo de uso do solo mais abundante, havendo predomínio do uso com pastagem.

O Planalto da Mantiqueira possui declividades, em sua maioria, acima de 30\% (Montanhoso), e entre $20 \%$ e $30 \%$ (Forte Ondulado), com altitudes variando entre 830 e 1.494 m, Escarpas do Planalto da Mantiqueira e os Blocos Serranos Intermediários são áreas com declividades acima de 30\% (Montanhoso) variando sua altitude entre 1.030 e $1.419 \mathrm{~m}$, e as Cristas e Escarpas Setentrionais são áreas com declividades maiores que 30\% (Montanhoso) e altitudes de 830 e $1.419 \mathrm{~m}$. Grande maioria do relevo encontrado nessas áreas possuem altas declividades, maiores que $45^{\circ}$, portanto, essas áreas devem ser preservadas como APP juntamente com as delimitações corretas nos cursos d'água e nascentes, as demais áreas podem ser transformadas em APA, pois garantiria o uso dos recursos naturais com sustentabilidade e ordenaria a ocupação.

Serras Baixas encontram-se entre as áreas mais planas e áreas mais íngremes, com declividade entre 20 e 30\% (Forte Ondulado) e altitudes entre 840 e $1.064 \mathrm{~m}$, por possuírem declividades mais elevadas, essas localidades necessitam de práticas conservacionistas para manter o equilíbrio ecológico, uma vez que o maior uso do solo é pastagem, levando a possível ocorrência de processos erosivos por conta do trilho do gado e impermeabilização do solo. 
XVII Simpósio Brasileiro

de Geografia Fisica Aplicada

I Congresso Nacional

de Geografia Fisica
OS DESAFIOS DA GEOGRAFIA FÍSICA NA FRONTEIRA DO CONHECIMENTO

Instituto de Geociências - Unicamp

Campinas - SP

28 de Junho à 02 de Julho de 2017

Colinas e Morros possuem declividades de 12 a 20\% (Ondulado), e altitudes de 820 a 1.120 m, com a manutenção de um manejo adequado essas áreas podem ser utilizadas com diferentes usos por um longo período.

Planície Fluvial possui declividade menor do que 6\% e altitude entre 820 e 960 m. Em decorrência da impermeabilização do solo e à retificação dos corpos d'água pela ocupação antrópica no município e na área urbana de Pouso Alegre, ocasionou mudança da dinâmica natural da planície fluvial, alterando o curso natural do rio Mandu, o que agravou o problema das enchentes e inundações típicas da área, cabendo ao poder público propor medidas eficazes. Nesta área a preservação da vegetação nativa e a recuperação das áreas degradadas são importantes para evitar desastres naturais.

Considerando a classe de declividade de maior relevância no Código Florestal, as áreas com declividade acima de $45^{\circ}$ representam $83,16 \mathrm{~km}^{2}$ (16,3\% da área total da Sub-bacia Hidrográfica do Rio Mandu). Desta forma, deveriam ser resguardadas como APP, porém nestas a mata nativa representa apenas $25,2 \%$, predominando também a pastagem com 63,3\% das áreas. São registrados usos com culturas temporárias $9,3 \%$, solo exposto $1,1 \%$, café $0,9 \%$, eucalipto $0,1 \%$ e área urbana $0,1 \%$.

As APP nos cursos d'água e nascentes também apresentam defasagem em relação ao Código Florestal, pois possuem apenas $22,3 \%$ com mata nativa e os demais usos sendo o café com 1,3\%, solo exposto 2,1\%, culturas temporárias $17,5 \%$, pastagem $55,2 \%$, eucalipto $0,2 \%$ e área urbana $1,4 \%$.

Apesar da função de manutenção da estabilidade dos sistemas ambientais, na prática, o atual Código Florestal, mais inseriu medidas que auxiliam interesses econômicos momentâneos do que às questões ambientais. Fato é que o aumento de desmatamento resulta em perdas na qualidade e quantidade de água, na formação de processos erosivos que diminuem a fertilidade e causa a perda de solos, na redução do habitat de insetos polinizadores, e esses fatores diminuem significativamente a produtividade agrícola a médio e longo prazo (ZANATTA; LUPINACCI; BOIN, 2016).

\section{Conclusão}

Apesar de o Código Florestal possui alguns desafios que remetem aos interesses que permearam sua elaboração, a aplicação das determinações legais atenuaria os impactos ambientais resultantes da ocupação do solo de áreas vulneráveis. Isto, considerando tanto as áreas de entorno de nascentes e cursos d'água e as de elevada declividade. 


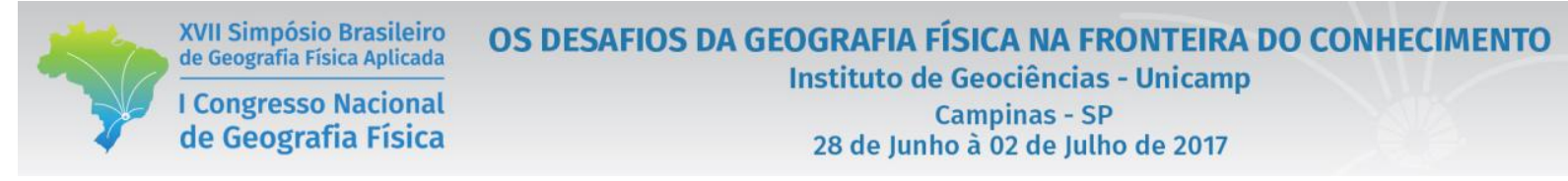

Em relação a Reserva Legal a área também não possui a quantidade mínima necessária para o bioma da Mata Atlântica, que é 20\% da área total, possui apenas 13\%. O Código Florestal atual não está sendo cumprido, prejudicando a manutenção do equilíbrio sistêmico.

\section{Bibliografia}

ANA. Agência Nacional de Águas. Brasil: Atlas do abastecimento urbano, 2015. Disponível:

$<$ http://atlas.ana.gov.br/atlas/forms/analise/Geral.aspx?est=8>. Acesso: 20 jan. 2017.

BERGER, A. R. Where is sustainability when landscapes change rapidly? Malásia: Institute of Environmental and Development, p. 1-32, 2007.

BRASIL. Novo Código Florestal Brasileiro. 2012. Lei no 12.651, de 25 de maio de 2012. Disponível em: <http://www.planalto.gov.br/ccivil_03/_ato2011-2014/2012/lei/112651.htm>. Acesso em: 07 jan. 2017.

CABRAL, J. B. P. et al. Mapeamento da fragilidade ambiental da bacia hidrográfica do Rio Doce (GO), utilizando técnicas de geoprocessamento. Madri: GeoFocus (Artículos), n. 11, p. 51-69, 2011.

CPRM. Companhia de Pesquisa de Recursos Minerais. Carta Geológica Guaratinguetá. São Paulo: Superintendência Regional CPRM. 1 mapa. Escala 1: 250.000. 1998.

FEAM - Fundação Estadual do Meio Ambiente. Mapa de solos do estado de Minas Gerais. Belo Horizonte, MG. 4 mapas. Escala: 1:650.000. 2010.

GOUVÊA, O. M. A História de Pouso Alegre. 2 ed. Gráfica Amaral: Pouso Alegre. 2004.

IBGE. Instituto Brasileiro de Geografia e Estatística. Cidades: Pouso Alegre. 2014. Disponível:

$<$ http://www.cidades.ibge.gov.br/xtras/perfil.php?lang=\&codmun=315250\&search=minas-gerais|pouso-alegre>. Acesso: 20 jan. 2017.

INSTITUTO BRASILEIRO DE GEOGRAFIA E ESTATÍSTICA - IBGE. Carta Topográfica de Conceição dos Ouros. Rio de Janeiro: IBGE, 1971a. 1 mapa. Escala 1:50.000.

.Carta Topográfica de Pouso Alegre. Rio de Janeiro: IBGE, 1971b. 1 mapa. Escala 1:50.000.

. Carta Topográfica de Santa Rita de Caldas. Rio de Janeiro: IBGE, 1972a. 1 mapa. Escala 1:50.000.

. Carta Topográfica de Ipuiuna. Rio de Janeiro: IBGE, 1972b. 1 mapa. Escala 1:50.000.

. Carta Topográfica de Borda da Mata. Rio de Janeiro: IBGE, 1972c. 1 mapa. Escala 1:50.000.

MACHADO, M.F. \& SILVA, S.F. Geodiversidade: Adequabilidade/Potencialidades e Limitações Frente ao Uso e à Ocupação. In: MACHADO, M.F., SILVA, S.F. (Org.), Geodiversidade do Estado de Minas Gerais. Belo Horizonte: Ministério de Minas e Energia, Secretaria de Geologia, Mineração e Transformação Mineral e Serviço Geológico do Brasil, p. 49-94, 2010.

MAGAlHÃeS Jr., A.P. \& DINIZ, A. A. Padrões e Direções de Drenagem na Bacia do Rio Sapucaí - Sul de Minas Gerais. GEONOMOS, v. 5, n. 2, p. 29-32, 1997.

MAGALHÃES Jr., A.P. \& DINIZ. Morfodinâmica Fluvial Cenozoica em Zonas de Contato entre Faixas Móveis e "Cunhas Tectônicas" na Região Sul de Minas Gerais. GEONOMOS, v. 13, n. 1, p. 59-74, 2005.

NASA. National Aeronautics and Space Administration, ASTER GDEM: Advanced Spaceborne Thermal and Reflection Radiometer Global Digital Elevation Map. 2015. Disponível: <http://asterweb.jpl.nasa.gov/>. Acesso: 15 jan. 2015.

PEREIRA, K. F. Zoneamento Geoambiental da Bacia Hidrográfica da Represa Laranja Doce - Martinópolis (SP). 2012. 108f. Dissertação (Mestrado em Geografia), USP, Rio Claro. 2012. 
RIBEIRO, A.S.; MINCATO, R.L.; CURI, N.; KAWAKUBO, F.S. Vulnerabilidade Ambiental à Erosão Hídrica em uma Sub-bacia Hidrográfica pelo Processo Analítico Hierárquico. Recife: Revista Brasileira de Geografia Física, v. 9, n. 1, p. 016-031, 2016.

RODRIGUEZ, J. M. M.; SILVA, E. D.; CAVALCANTI, A. P. B. Geoecologia da paisagem: uma visão geossistêmica da análise ambiental. Fortaleza: EDUFC, 2002.

ROSS, J. L. S. Análise empírica da fragilidade dos ambientes naturais e antropizados. São Paulo: Revista do Departamento de Geografia, FFLCH-USP, n. 8, 1994.

ROSS, J. L. S. Landforms and Environmeental Planning:potentialities and fragilities. In: Revista do Departamento de Geografia, São Paulo, FFLCH-USP, volume especial de 30 anos, p. 38-51, 2012.

ROSS, J. L. S. O Registro Cartográfico dos Fatos Geomórficos e a Questão da Taxonomia do Relevo. São Paulo: Revista do Departamento de Geografia (USP), São Paulo, v. 06, 1992.

RUFINO, R. C. Avaliação da qualidade ambiental do município de Tubarão (SC) através do uso de indicadores ambientais. 2002. 113f. Dissertação (Mestrado em Engenharia de Produção), UFSC, Florianópolis. 2002.

ZANATTA, F. A. S.; LUPINACCI, C. M.; BOIN, M. N. Geoecologia da Paisagem X Legislação Ambiental: Uma Análise da Distribuição Espacial das Restrições ao Uso da Terra Frente à Problemática Erosiva na Alta Bacia do Ribeirão Areia Dourada, Marabá Paulista (SP). Uberlândia: Revista Sociedade \& Natureza, v. 1, n. 28, p. 2138, jan./abr. 2016. 